\title{
Role of Radiotherapy With Surgery for T3 and Resectable T4 Rectal Cancer: Evidence From Randomized Trials
}

\author{
Cecile Ortholan, M.D., ${ }^{1}$ Eric Francois, M.D., ${ }^{2}$ Olivier Thomas, M.D., ${ }^{1}$ \\ Daniel Benchimol, Ph.D., M.D., ${ }^{3}$ Jacques Baulieux, M.D., ${ }^{4}$ Jean F. Bosset, M.D., ${ }^{5}$ \\ Jean P. Gerard, M.D. ${ }^{1}$ \\ ${ }^{1}$ Department of Radiotherapy, Centre Antoine-Lacassagn, Nice, France \\ ${ }^{2}$ Department of Oncology, Centre Antoine-Lacassagne, Nice, France \\ ${ }^{3}$ Department of Surgery, Centre Hospitalier Universitaire de Nice, Nice France \\ ${ }^{4}$ Department of Surgery, Centre Hospitalier Universitaire de Lyon, Lyon France \\ ${ }^{5}$ Department of Radiotherapy, Centre Hospitalier Universitaire de Besancon, Besancon France
}

PURPOSE: The main treatment for resectable rectal cancer T2-T4 NO-N2 M0 is surgery. The benefit of preoperative or postoperative radiation therapy can be analyzed in terms of improvement of local control, sphincter preservation, and survival weighted against increased toxicity. METHODS: Only randomized trials can provide strong evidence of a positive cost-benefit ratio of such combined approach. The most recent trials were reviewed. RESULTS: Three randomized trials, including the latest German CAO-ARO trial, have demonstrated the superiority of preoperative radiotherapy with or without chemotherapy (vs. postoperative) in terms of local control and toxicity. The Ducth TME trial showed that even with modern standard surgery, preoperative radiotherapy improved local control. Preoperative irradiation using a high dose in a small volume and a long interval before surgery may improve sphincter preservation (Lyon trials). Concurrent chemoradiation (FFCD 9203, EORTC 22921, did not significantly improve sphincter preservation or survival but significantly reduced the local recurrence rate. CONCLUSIONS: In 2005 examination of randomized trials provides evidence for the benefit of preoperative chemoradiation in improving local control and probably sphincter preservation in rectal cancer. Randomized trials should be designed to further demonstrate improved sphincter preservation and to increase survival using

Correspondence to: Jean Pierre Gerard, Centre Antoine Lacassagne, 33 avenue de Valombrose, 06189, Nice Cedex 02, France, e-mail: jean-pierre.gerard@cal.nice.fnclcc.fr adjuvant medical treatments. [Key words: Radiotherapy; Chemotherapy; Rectal cancer; Preoperative; Sphincter saving; Local control

$\mathrm{R}$ ectal cancer is a frequent disease representing in Western countries 15 percent of gastrointestinal cancers and 4 percent of all cancers. The main treatment is surgery, and improvements made during the past 20 years have decreased postoperative death from 10 percent to 2 percent, local relapse from 30 to 40 percent to less than 15 percent, and increased rate of conservative surgery from 20 percent to 50 to 60 percent. The standard surgical treatment for T2, T3, and "resectable T4" is careful, sharp dissection under visual control along anatomic plane without disturbing the perirectal fascia; this is called total mesorectal excision (TME). ${ }^{1}$

The question of preoperative or postoperative radiotherapy with or without chemotherapy has been under consideration for many years. In the 1990s several randomized trials reported the benefit of postoperative adjuvant chemoradiotherapy for local control and overall survival. Postoperative chemoradiotherapy became the standard treatment in the United States. ${ }^{2-4}$ In Europe, the Swedish trial and a meta-analysis demonstrated the benefit of preoperative radiotherapy in terms of local relapse and overall 
survival. ${ }^{5,6}$ However, these results and conclusions were established before the time of TME surgery, therefore, the benefit of adjuvant and neoadjuvant treatment associated with TME is still under debate. The benefit should be analyzed in terms of relevant end points for the patients: local control, sphincter preservation, sphincter function, survival, toxicity, and quality of life. Only randomized trials can be used to give proper answers to these questions.

This is a review of some past and all recent data from phase III trials with the aim of determining the present role of radiotherapy (and chemotherapy) in rectal cancer treated using modern surgery.

\section{PREOPERATIVE $V S$. POSTOPERATIVE RADIOTHERAPY}

Three randomized trials compared preoperative $v s$. postoperative treatment. In the Uppsala trial patients were allocated to receive either short-course preoperative radiotherapy ( $25 \mathrm{~Gy}$ in 5 fractions) or postoperative radiotherapy (60 Gy: 40 Gy plus a 20Gy boost). Preoperative radiotherapy significantly decreased the local recurrence rate relative to postoperative radiotherapy, with a reduced rate of late morbidity. ${ }^{7,8}$ The NSABP R03 trial compared preoperative chemoradiotherapy (fluorouracil $(5 \mathrm{FU})+$ leucovorin (LV), 50.4 Gy) to the same regimen given postoperatively. Overall treatment-related toxicity was similar in both groups, and there was a trend to tumor downstaging and sphincter preservation in the preoperative arm. Because only 267 patients of 900 were included in this trial, data on long-term toxicity and survival are not available.

The most extensive trial is the $\mathrm{CAO} / \mathrm{ARO} / \mathrm{AIO}$ trial that compared preoperative to postoperative chemoradiotherapy in patients with rectal cancer (T1-T4, low, middle, and high rectum). The first end point of this trial was overall survival. In the preoperative group, patients received 50.4 Gy with two cycles of concurrent $5 \mathrm{FU}$ protracted venous infusion (PVI) and four additional adjuvant cycles of bolus $5 \mathrm{FU}$. In the postoperative group patients received 55.8 Gy with the same concurrent and additional chemotherapy regimen. All patients underwent standardized TME surgery. Eight hundred twenty-three patients were included in this study. Ninety-two percent in the preoperative arm $v s .54$ percent in the postoperative arm received a full dose of radiotherapy $(p<0.001)$ and 89 percent $v s .50$ percent received a full dose of chemotherapy $(p<0.001)$. There was a significantly decreased rate of acute and chronic toxicity with preoperative chemoradiotherapy. With a five-year local recurrence rate of 13 percent in postoperative arm $v s .6$ percent in preoperative arm $(p=0.006)$, it can be assumed that preoperative chemoradiotherapy significantly improved local control compared with postoperative. No benefit in terms of overall survival was observed. The rate of sphincter preservation in a subgroup analysis including 194 patients with low lying tumors declared by the surgeon before randomization as needing an abdominoperineal resection was increased (39 percent vs. 19 percent, $p=0.004)$. However, taking into consideration all 799 patients, the rate of use of a sphinctersaving procedure (SSP) was 71 percent in the postoperative arm and 69 percent in the preoperative arm. Because of the double consent design of Zelen, the two arms of this subgroup are not exactly comparable. Therefore, conclusions regarding SSP in this trial have no solid foundation. ${ }^{10}$

Results of these three randomized trials demonstrated clearly the superiority of preoperative radiotherapy regimen compared with postoperative in terms of local control with better compliance to treatment and lower toxicity (Table 1 ).

\section{THE DUTCH TRIAL WITH TME}

Before the use of TME surgery, local recurrence rate for locally advanced rectal cancer was approximately 30 percent. Heald obtained a five-year local recurrence rate with TME surgery alone close to 5 percent. ${ }^{1}$ This result led to questioning the benefit of neoadjuvant therapy. The Dutch trial had the merit of randomizing 1861 patients with TNM Stage I to IV who received either short-course radiotherapy ( 25 Gy, 5 Gy per fractions in 5 days) followed by well-standardized TME $v s$. TME alone. The rate of local recurrence at five years was 5.8 percent in the radiotherapy group and 11.3 percent in the surgeryalone group $(p<0.001)$, but this difference did not improve overall survival ${ }^{11,12}$ (Table 2). Subgroup analysis showed no benefit for local recurrence of preoperative radiotherapy in patients with a positive circumferential tumor margin or with cancer in the lower rectum. In fact, the major bias of this trial concerns 47 percent of patients in the surgery-alone group with positive circumferential rectal margin $(\leq 1 \mathrm{~mm})$ who received postoperative radiotherapy 
Table 1.

Preoperative vs. Postoperative Radiotherapy

\begin{tabular}{|c|c|c|c|c|c|c|}
\hline & \multicolumn{2}{|c|}{ Uppsala $^{7,8}$} & \multicolumn{2}{|c|}{ NSABP-R03 ${ }^{9}$} & \multicolumn{2}{|c|}{$\mathrm{CAO} / \mathrm{ARO} / \mathrm{AIO}-94^{10}$} \\
\hline & Preoperative & Postoperative & Preoperative & Postoperative & Preoperative & Postoperative \\
\hline Treatment & $\begin{array}{l}\text { RT } 25 \text { Gy } \\
\text { (1 week) }\end{array}$ & $\begin{array}{l}\text { RT } 60 \text { Gy } \\
\text { (8 weeks) }\end{array}$ & CRT 50 Gy & CRT 50 Gy & CRT 50 Gy & CRT 55 Gy \\
\hline No. of patients & 236 & 235 & 130 & 137 & 405 & 394 \\
\hline $\begin{array}{l}\text { Acute toxicity G3-4 } \\
\text { Postoperative }\end{array}$ & - & - & $34 \%$ & $23 \%(p=0.07)$ & $27 \%$ & $40 \%(p=0.001)$ \\
\hline $\begin{array}{l}\text { complications } \\
\text { Late toxicity }\end{array}$ & - & - & $25 \%$ & $22 \%$ (ns) & $36 \%$ & $34 \%(n s)$ \\
\hline Grades 3-4 & $20 \%$ & $41 \%(p=0.05)$ & - & - & $14 \%$ & $24 \%(p=0.01)$ \\
\hline pTO NO & - & - & $10 \%$ & $0 \%$ & $8 \%$ & $0 \%(p<0.001)$ \\
\hline SSP & - & - & $44 \%$ & $34 \%(n s)$ & $\begin{array}{l}69 \% \\
39 \% \\
\quad \text { (Subgrc }\end{array}$ & $\begin{array}{l}71 \% \\
19 \%(p=0.004) \\
\text { up of } 194 \text { pts })\end{array}$ \\
\hline $\begin{array}{l}\text { Five-year local } \\
\text { recurrence } \\
\text { Five-year overall }\end{array}$ & $13 \%$ & $22 \%(p=0.02)$ & - & - & $6 \%$ & $13 \%(p=0.006)$ \\
\hline survival & $47 \%$ & $40 \%(n s)$ & $74 \%$ & $66 \%(n s)$ & $76 \%$ & $74 \%(n s)$ \\
\hline
\end{tabular}

Table 2.

Results of the Dutch Trial $^{12}$

\begin{tabular}{|c|c|c|c|}
\hline & TME & $\mathrm{TME}+\mathrm{RT}$ & \\
\hline Patients & 937 & 924 & \\
\hline $\begin{array}{l}\text { Sphincter preservation } \\
\text { Five-year local }\end{array}$ & $67 \%$ & $65 \%$ & \\
\hline recurrence rate & $11.4 \%$ & $5.8 \%$ & $P<0.001$ \\
\hline $\begin{array}{l}\text { Five-year distant } \\
\text { recurrence rate }\end{array}$ & $28.2 \%$ & $25.5 \%$ & ns \\
\hline Five-year overall survival & $63.5 \%$ & $64.3 \%$ & ns \\
\hline
\end{tabular}

$\mathrm{TME}=$ total mesorectal excision; RT = radiotherapy.

(50.4 Gy/6 weeks); therefore, it is difficult to conclude that in such a situation preoperative radiotherapy does not compensate for a positive circumferential rectal margin. ${ }^{13}$

Long-term results of the Dutch trial showed fecal incontinence in 62 percent of patients in the irradiated group and in 39 percent of the surgery-alone group ( $p$ $<0.001$ ). Radiotherapy decreased sexual function in both men and women. These results are in agreement with the analysis of adverse effects of preoperative radiotherapy in the Swedish trial. ${ }^{14}$ However, it may be possible that the large irradiated volume and the high dose per fraction ( 5 Gy) in theses two trials are partially responsible for this toxicity. A radiation technique that avoids irradiating the perineum, the anal canal, and part of the small bowel as much as possible could minimize bowel dysfunction.

Thus, it is highly probable that preoperative radiotherapy, even with the use of standardized TME surgery, is beneficial in the vast majority of
T3-T4 rectal cancers. Important questions arising from this trial are: Can we further improve local control and, more importantly, survival and sphincter preservation with delayed surgery, radiation dose escalation, or concurrent chemotherapy?

\section{RADIOTHERAPY AND SPHINCTER PRESERVATION}

One important issue for patients with rectal cancer is sphincter preservation. It has generally been recommended that the surgeon leave a R0 circumferential rectal margin and distal margin of at least $2 \mathrm{~cm}$ from the tumor to yield at least a $1-\mathrm{cm}$ margin, as measured by the pathologist. ${ }^{15}$ Different schedules of preoperative radiotherapy have been correlated with the rate of use of a sphincter-sparing procedure.

\section{IMMEDIATE $V \boldsymbol{S}$. DELAYED SURGERY AFTER RADIOTHERAPY}

None of the randomized trials that compare surgery alone with preoperative radiotherapy and immediate surgery showed any difference in the SSP. The analysis of the data of the recent Dutch and Swedish trials revealed that short-course radiotherapy followed by immediate surgery does not lead to a significant clinical and pathologic tumor response., ${ }^{5,13}$ It can be hypothesized that a long interval before surgery is necessary to allow for a tumor response and to improve chances of sphincter preservation. 
To assess the optimum interval between radiotherapy and surgery, the Lyon R90-01 trial compared a short delay with a long delay after preoperative radiotherapy. The main end point was conservative surgery. Two hundred one patients with T2-T3 tumors in the lower rectum were allocated to receive surgery either two weeks after completion of radiotherapy (39 Gy in 13 fractions delivered over 17 days) or six to eight weeks after the same regimen of radiotherapy. The long interval was associated with a significantly better clinical response (53 percent $v$ s. 72 percent, $p=0.007$ ), and pathologic downstaging (10 percent $v s$. 26 percent, $p=0.005$ ). There was a trend in favor of a long interval with increased sphincter preservation (76 percent vs. 68 percent, $p=0.27$. Local control and the incidence of complications were the same in both arms. However, when the distal margin from the tumor after anterior resection was less or more than $15 \mathrm{~mm}$ on the operative specimen, the rate of local recurrence was, respectively, 16 percent and 8 percent. After five years of follow-up there was no difference in overall survival between the two arms. ${ }^{16}$

These data suggest that delayed surgery is not detrimental to survival and could increase the chance of performing a SSP, taking advantage of the tumor response. A delay of six weeks could be recommended. The difficult question remains: To what extent can the surgeon dissect close to the tumor margin without compromising too much the chance of local control?

\section{RADIATION DOSE ESCALATION}

Based on the evidence that higher radiation doses improve tumor response and local control in other tumor locations, ${ }^{17,18}$ radiation dose escalation has been evaluated in rectal cancer. The limitation of high-dose radiotherapy is acute and late toxicities in the pelvic region. However, even with an optimal technique that uses conformal intensity-modulated radiotherapy, dose escalation is limited in the pelvis by rectal tolerance. Contact X-ray is an attractive and simple way to deliver a high dose in a very small volume $(<4 \mathrm{ml})$ in rectal cancer. Supported by the evidence of retrospective studies, ${ }^{19}$ the Lyon R96-02 allocated 88 patients with $\mathrm{T} 2$ and $\mathrm{T} 3$ low-lying tumors not exceeding two thirds of the circumference to receive either preoperative external beam radiotherapy alone (EBRT) (39 Gy in 13 fractions) vs. the same EBRT with a contact X-ray boost ( 85 Gy in 3 fractions). A complete clinical response was found in 13 of 45 patients (29 percent) in the experimental group vs. 1 of 43 (2 percent) with EBRT alone $(p=0.01)$. Seven patients in the contact X-ray group did not undergo surgery but a brachytherapy boost to terminate the treatment, and a local excision was performed in three patients in the contact X-ray group because of complete clinical response. The overall rate of SSP was 76 percent in the contact boost group vs. 44 percent in the EBRTalone group $(p=0.004)$. No difference in terms of morbidity, sphincter function, local relapse, and twoyear overall survival was observed ${ }^{20}$ (Table 3 ).

\section{CONCURRENT CHEMORADIOTHERAPY}

Tolerance of concurrent chemotherapy using a 5FU regimen in addition to preoperative radiotherapy has been evaluated in several phase II trials. ${ }^{21,22}$ Results observed for acute toxicity and postoperative morbidity allowed the conclusion that preoperative

Table 3.

Results of the LYON R96-02 Trial $^{20}$

\begin{tabular}{|c|c|c|c|}
\hline & RT & RT + Endocavitary X-Ray Boost & \\
\hline Patients & 43 & 45 & \\
\hline Complete clinical response & $1(2 \%)$ & $13(29 \%)$ & \\
\hline \multicolumn{4}{|l|}{ Surgery } \\
\hline Transanal excision & 0 & 3 & \\
\hline Anterior resection & 19 & 24 & \\
\hline Abdominoperineal resection & 24 & 11 & \\
\hline Radiotherapy alone & 0 & 7 ( 1 for distant metastasis) & \\
\hline Complete sterilization & $3 / 43(7 \%)$ & $16 / 45(35 \%)^{a}$ & \\
\hline Overall SSP rate & $44 \%$ & $76 \%$ & $p=0.004$ \\
\hline Sphincter function good/excellent & $14 / 19$ & $22 / 27$ & \\
\hline Two-year local recurrence-free survival & $88 \%$ & $92 \%$ & \\
\hline
\end{tabular}

$\mathrm{RT}=$ radiotherapy; SSP $=$ sphincter-saving procedure.

${ }^{a}$ Including patients treated with transanal excision and radiotherapy alone. 
chemoradiotherapy was feasible. Moreover, the rate of complete pathologic response between 10 and 20 percent led to the hypothesis that neoadjuvant chemoradiotherapy could improve SSP and local control. Some retrospective studies strongly supported this hypothesis. ${ }^{23-25}$ Two randomized trials initiated in 1992 that compared preoperative radiotherapy alone with preoperative chemoradiotherapy have recently concluded and their results presented in oral communication. ${ }^{27,28}$

2005 in the EORTC 22921 trial included 1011 patients in a $2 \times 2$ factorial plan: preoperative treatment with radiotherapy alone ( $45 \mathrm{~Gy} / 5$ weeks) $v s$. radiotherapy + concurrent chemotherapy $(5 \mathrm{FU}$ $350 \mathrm{mg} / \mathrm{m}^{2} / \mathrm{d}$ intravenous bolus_folinic acid $20 \mathrm{mg} /$ $\mathrm{m}^{2} / \mathrm{d}$, Days 1 to 5 in the first and fifth weeks of radiotherapy) and postoperative treatment with four cycles of chemotherapy (5FU + folinic acid) $v s$. no adjuvant chemotherapy. Acute toxicity was moderately increased in the chemoradiotherapy arm. ${ }^{26}$ The five-year results showed that chemotherapy increased the rate of a complete pathologic response: 14 percent $v s .5 .3$ percent, $p=0.001$, translated into a 3 percent benefit in terms of sphincter preservation ( 52.4 percent $v s .55 .6$ percent, $p=0.05$ ) and significantly reduced the five-year local failure rate from 17 percent without chemotherapy down to 8 percent with chemotherapy. For five years postoperative chemotherapy had no significant effect on survival. ${ }^{27}$

The FFCD 9203 trial included 762 patients, with only a preoperative randomization. It used the same
EORTC chemotherapy regimen $\left(5 \mathrm{FU} 350 \mathrm{mg} / \mathrm{m}^{2} / \mathrm{d}\right.$ IV bolus-folinic acid $20 \mathrm{mg} / \mathrm{m}^{2} / \mathrm{d}$ ) concurrently with radiotherapy ( $45 \mathrm{~Gy} / 5$ weeks) $v$ s. radiotherapy alone. Seventy percent of patients received adjuvant chemotherapy ( 4 cycles of $5 \mathrm{FU}+$ folinic acid) initially scheduled for all patients. The primary end point was as in the EORTC trial, i.e., to increase the five-year overall survival rate of 10 percent. Grades 3 to 4 acute toxicity was increased in the chemoradiotherapy arm. The five-year results showed that chemotherapy increased the rate of complete pathologic response: 11.7 percent $v s .3 .7$ percent, $p=0.05$, with the same rate of sphincter preservation (52 percent in each arm) and significantly decreased the rate of local recurrence from 16.5 percent to 8 percent (Table 4). Moreover, between 1999 and 2003, a majority of patients received standardized TME surgery and the rate of local recurrence was 14 percent in the radiotherapy arm $v$ s. 5 percent in the radiochemotherapy arm. ${ }^{28}$

A third randomized trial, the Polish trial which concluded in 2002, compared high-dose radiotherapy plus concurrent chemotherapy followed by delayed TME surgery (50.4 Gy/6 weeks) to shortcourse radiotherapy with immediate TME surgery (25 Gy/5 fractions). Opposite the two previously discussed trials, this study was designed to answer the question of sphincter preservation as the first end point. Results showed that despite a significant increase in the rate of complete pathologic response (15 vs. 1 percent, $p<0.001$ ) there was no benefit in sphincter preservation: the SSP rate was 61 percent in the radiotherapy-alone arm and 58 percent in the

Table 4.

Preoperative Radiotherapy vs. Chemoradiotherapy

\begin{tabular}{|c|c|c|c|c|c|c|}
\hline & \multicolumn{2}{|c|}{ EORTC $22921^{26,27}$} & \multicolumn{2}{|c|}{ FFCD $92-03^{28}$} & \multicolumn{2}{|c|}{ Polish Trial ${ }^{29}$} \\
\hline & RT 45 Gy & $\begin{array}{l}\text { RT45 Gy + } \\
\text { FuFol }\end{array}$ & RT 45 Gy & $\begin{array}{c}\text { RT } 45 \text { Gy + } \\
\text { FuFol }\end{array}$ & $\begin{array}{c}\text { RT } 25 \text { Gy } \\
\text { Short Course }\end{array}$ & $\begin{array}{c}\text { RT } 50.4 \text { Gy + } \\
\text { FuFol }\end{array}$ \\
\hline $\begin{array}{l}\text { No. of patients } \\
\text { Preoperative } \\
\quad \text { toxicity }\end{array}$ & 505 & 506 & 363 & 370 & 148 & 138 \\
\hline $\begin{array}{l}\text { Grade } \geq 2 \\
\text { Grade 3-4 }\end{array}$ & $37 \%$ & $54 \%(p=0.005)$ & $2 \%$ & $14 \%(p=0.001)$ & $3 \%$ & $18 \%(p<0.001)$ \\
\hline $\begin{array}{l}\text { Surgery } \\
\text { ypTO No } \\
\text { SSP rate }\end{array}$ & $\begin{array}{r}98 \% \\
5.3 \% \\
52.4 \%\end{array}$ & $\begin{array}{l}99 \% \\
14 \%(p<0.001) \\
55.6 \%(p=0.05)\end{array}$ & $\begin{array}{l}99 \% \\
3.7 \% \\
51.7 \%\end{array}$ & $\begin{array}{l}97 \%(p=0.01) \\
11.7 \%(p<0.001) \\
52.6 \%(\mathrm{~ns})\end{array}$ & $\begin{array}{r}99 \% \\
1 \% \\
61 \%\end{array}$ & $\begin{array}{l}97 \% \\
16 \%(p<0.001) \\
58 \%(\mathrm{~ns})\end{array}$ \\
\hline $\begin{array}{l}\text { Five-year local } \\
\text { recurrence } \\
\text { Five-year } \\
\text { overall }\end{array}$ & $17 \%$ & $8 \%(p=0.002)$ & $16.5 \%$ & (2) & $?$ & (10) (10) \\
\hline survival & $65.6 \%$ & $64.8 \%$ (ns) & $66.6 \%$ & $67.8 \%$ & $?$ & $?$ \\
\hline
\end{tabular}

$\mathrm{RT}=$ radiotherapy; FuFol $=5 \mathrm{FU}+$ folinic acid; EORTC = European Organization for Research and Treatment on Cancer; FFCD = Fédération Française de Cancérologie Digestive; SSP = sphincter-saving procedure. 
chemoradiotherapy $\operatorname{arm}(p=0.57)$. Two explanations could be given for these negative results: First, surgeons did not want to reappraise their indication of abdominoperineal resection (APR) depending on the clinical tumor response after neoadjuvant chemoradiotherapy, and, second, the clinical tumor response with concurrent chemotherapy could have been too small to influence the surgical decision. Local control and survival results are expected in this trial at the end of $2005 .{ }^{29}$

\section{DISCUSSION}

Surgery will remain for many years the cornerstone of rectal cancer treatment. In the era of modern TME surgery, the benefit of preoperative or postoperative radiotherapy with or without chemotherapy appears to be modest and not yet definitively established. At the present time, results from randomized trials for low and middle T3 rectal cancer and "resectable" T4 rectal cancer are as follows:

- Even with TME surgery the majority of rectal tumors below the peritoneal reflexion (accessible to digital rectal examination) should be treated with preoperative radiotherapy. The best technique (dose, fractionation, volume) of radiotherapy is still under discussion. Preoperative radiotherapy with TME surgery improves local control but has no impact on overall survival. ${ }^{11,12}$

- Preoperative radiotherapy is superior to postoperative radiotherapy in terms of local control and toxicity. ${ }^{7-10}$

- The advantage of preoperative chemoradiotherapy in terms of local control compared with radiotherapy alone is now proven in locally advanced rectal cancer. It is also possible that it brings a small benefit to the SSP, but overall survival is not yet modified by preoperative chemotherapy. At the present time chemoradiation could be considered as the standard preoperative treatment for $\mathrm{T} 3-\mathrm{T} 4$ resectable cancers. ${ }^{27-29}$

Sphincter preservation is a very complex issue because it depends on many factors: characteristics of the tumor, age, gender, morphology, and psychology of the patients and experience of the surgeon. Results of the Dutch and Swedish trials demonstrated that preoperative radiotherapy followed by immediate surgery does not increase sphincter preservation., ${ }^{5,11}$ The only radiotherapy modality that has been shown to be beneficial for sphincter preservation is radiation dose escalation and there are arguments in favor of SSP with delayed surgery after radiotherapy. Many institutions are using preoperative chemoradiation and recent results of randomized trials show no clear benefit of SSP with the addition of chemotherapy. Moreover, the Polish trial, which compared the best approach of SSP (high-dose radiotherapy, concurrent chemotherapy, and delayed surgery) to the less optimal approach (short-course radiotherapy alone, immediate surgery), did not show any benefit to using SSP. The increased rate of complete pathologic response

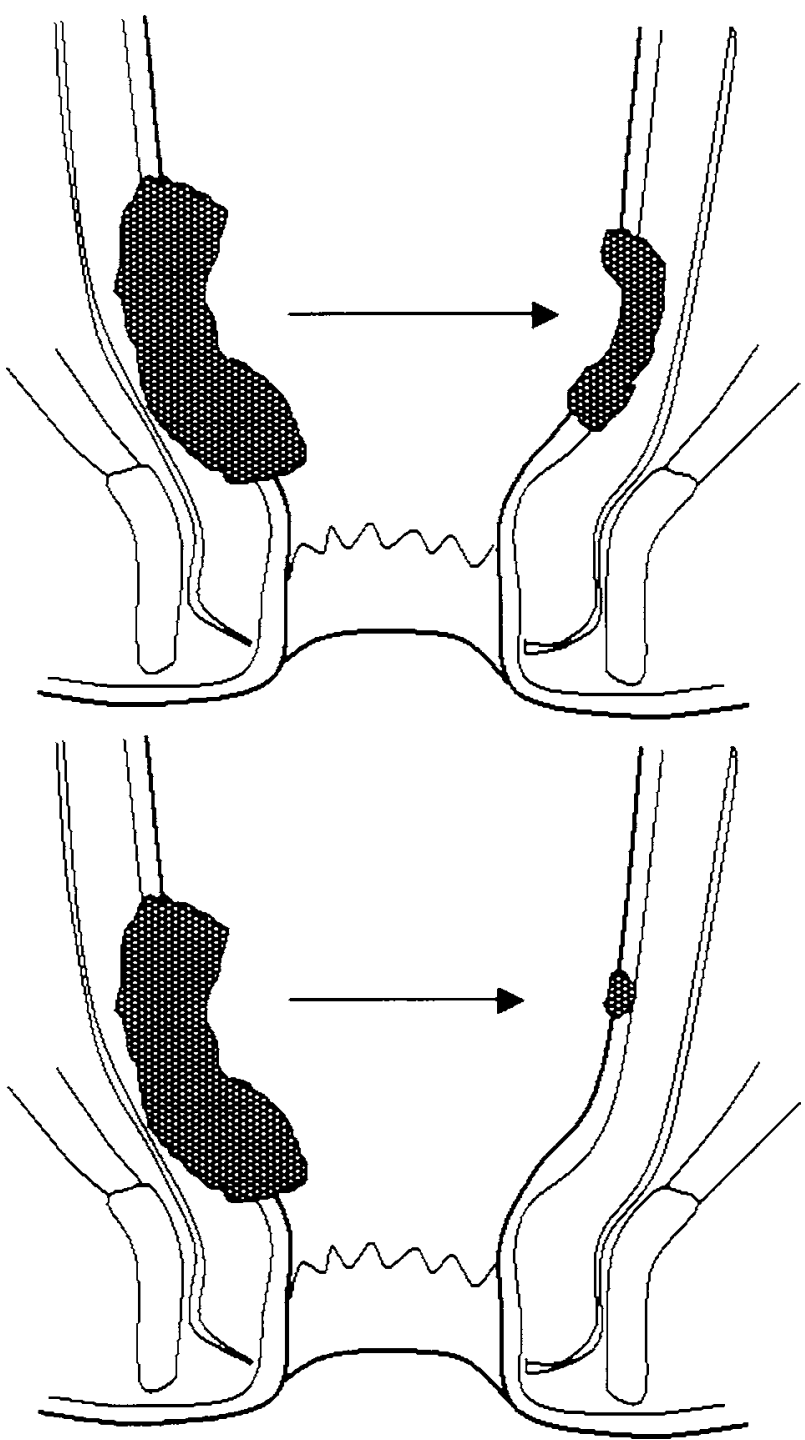

Figure 1. Clinical tumor response after neoadjuvant treatment may influence the surgeon's decision and increase the chance of sphincter preservation. Top. (left) Tumor before neoadjuvant treatment, (right) partial clinical tumor response: little change in the surgeon's decision to perform APR (abdominoperineal resection). Bottom. (left) Tumor before neoadjuvant treatment, (right) major clinical tumor response: possible change in the surgeon's decision to perform APR. 
with concurrent chemotherapy did not correlate with a higher rate of SSP. ${ }^{28}$ It is possible that the most relevant predictive factor for SSP could be the clinical tumor response after neoadjuvant treatment. A new hypothesis could be to test, in a clinical trial, if the surgeon's decision to perform APR could be reappraised after a major or complete clinical tumor response before the operation (Fig. 1).

The question of preoperative concurrent chemotherapy is still open. The three trials that compared chemoradiotherapy with radiotherapy were designed with single-agent chemotherapy and a suboptimal schedule of 5FU. There are a number of new agents that have been developed for the treatment of patients with colorectal cancer such as capecitabine, oxaliplatin, and CPT11. Several phase I and phase II trials demonstrated the feasibility of neoadjuvant chemoradiation with polychemotherapy. ${ }^{30-32}$ Rodel, using preoperative chemoradiotherapy (50.4 Gy/6 weeks) plus weekly capecitabine and oxaliplatin, observed a complete pathologic response rate of 19 percent. ${ }^{33}$ Moreover, new agents such as targeted biotherapy were beneficial in metastatic colorectal cancer, and prospective studies will have to prove beneficial in neoadjuvant treatment in combination with radiotherapy. ${ }^{34}$ Using the pathologic complete response (tumor sterilization) on the operative specimen as a surrogate end point for local control and/ or (disease-free) survival could be an option, but it should be remembered that the pathologic tumor response is only a marker (and not a cause) of prognosis. It reflects but does not influence local control or survival.

At the present time, none of the neoadjuvant modalities of treatment associated with TME surgery has demonstrated benefit in terms of metastasis-free survival and overall survival. One explanation could be that the total dose of chemotherapy in preoperative chemoradiotherapy is not high enough to control metastases. Moreover, with the rate of local relapse being below 20 percent in both arms, a 50 percent improvement with chemotherapy is too low to influence survival at five years. The QUAZAR trial, which compared adjuvant chemotherapy with $5 \mathrm{FU}$ $v s$. no adjuvant treatment in colorectal cancer, showed there to be a small benefit for local recurrence and overall survival for adjuvant postoperative chemotherapy. ${ }^{35}$ However, results of the AXIS trial that compared postoperative portal venous infusion in colorectal cancer, showed there to be a benefit in terms of overall survival for colon cancer only, suggesting that rectal and colon cancers could have a different profile for a chemotherapy response. ${ }^{36}$ New phase III trials must be designed specifically for rectal cancer with new adjuvant chemotherapy and targeted biotherapy (Table 5).

Table 5.

Ongoing and Tentative Phase III Trials

\begin{tabular}{|c|c|c|c|}
\hline & Preoperative TTT & Surgery & Postoperative TTT \\
\hline \multirow[t]{2}{*}{ MRC CR 07} & RT 25 Gy/5 weeks & TME & - \\
\hline & - & TME & RT 45 Gy + 5FU/folinic acid \\
\hline ACCORD 12 & $\begin{array}{l}\text { RT } 45 \text { Gy + Capecitabine } \\
\text { RT } 50 \text { Gy + Capox }\end{array}$ & $\begin{array}{l}\text { TME } \\
\text { TME }\end{array}$ & $\begin{array}{l}\text { Postop CT free in each institution } \\
\text { Postop CT free in each institution }\end{array}$ \\
\hline ACOSOG & $\begin{array}{l}\text { RT } 50 \text { Gy + Capox + Capox } \times 2 \\
\text { RT } 50 \text { Gy + Capox }\end{array}$ & $\begin{array}{l}\text { TME } \\
\text { TME }\end{array}$ & $\begin{array}{l}\text { Capox } \times 2 \\
\text { Capox } \times 4\end{array}$ \\
\hline Italy & $\begin{array}{l}\text { RT } 50.4 \text { Gy + } 5 \text { Fu PVI } \\
\text { RT } 50.4 \text { Gy + } 5 \text { Fu oxaliplatin }\end{array}$ & $\begin{array}{l}\text { TME } \\
\text { TME }\end{array}$ & - \\
\hline Swedish & $\begin{array}{l}25 \mathrm{~Gy} / 1 \text { week } \\
25 \mathrm{~Gy} / 1 \text { week } \\
45 \mathrm{~Gy} / 5 \text { weeks }\end{array}$ & $\begin{array}{l}\text { Immediate TME } \\
\text { Delayed TME } \\
\text { Delayed TME }\end{array}$ & - \\
\hline RTOG 0247 & $\begin{array}{l}\text { RT } 50 \text { Gy + Capeiri } \\
\text { RT } 50 \text { Gy + Capox }\end{array}$ & $\begin{array}{l}\text { TME } \\
\text { TME }\end{array}$ & $\begin{array}{l}\text { FOLFIRI } \\
\text { FOLFOX }\end{array}$ \\
\hline TROG 44 & $\begin{array}{l}\text { RT } 25 \text { Gy/1 week } \\
\text { RT } 50 \text { Gy + 5Fu PVI }\end{array}$ & $\begin{array}{l}\text { Immediate TME } \\
\text { Delayed TME }\end{array}$ & - \\
\hline NSABP R-04 & $\begin{array}{l}\text { RT 50.4 Gy + Capecitabine } \\
\text { RT } 50.4 \text { Gy + } 5 \text { FU PVI }\end{array}$ & $\begin{array}{l}\text { TME } \\
\text { TME }\end{array}$ & - \\
\hline PROCTOR & $\begin{array}{l}\text { RT } 25 \text { Gy/1 week } \\
\text { RT } 25 \text { Gy/1 week + Capecitabine }\end{array}$ & $\begin{array}{l}\text { TME } \\
\text { TME }\end{array}$ & - \\
\hline German & $\begin{array}{l}50.4 \text { Gy + FU } \\
50.4 \text { Gy + Capox }\end{array}$ & $\begin{array}{l}\text { TME } \\
\text { TME }\end{array}$ & $\begin{array}{l}\text { FU } \\
\text { Capox }\end{array}$ \\
\hline
\end{tabular}

$\mathrm{RT}=$ external beam radiotherapy; TME = total mesorectal excision; $\mathrm{CT}=$ chemotherapy; Capox = capecitabine + oxaliplatin; Capeiri = capecitabine+irinotecan; PVI = protracted venous infusion; TTT = treatment. 
In conclusion, the evidence from randomized trials for a role of radiotherapy and chemotherapy with surgery in T3 and resectable T4 rectal cancers is still open to discussion. For local control, the Dutch trial favors preoperative radiotherapy for every patient, but because of radiation toxicity, criteria of selection could be defined (MRI?) to try to select patients for whom preoperative treatment could be avoided (T2 and "small" T3 of the upper rectum). Moreover, the recent FFCD 9203 and EORTC 22921 trials showed significant improvement in local control for T3-T4 resectable rectal cancer of the distal and middle rectum with concurrent chemotherapy and preoperative radiotherapy. Such a preoperative schedule could be considered standard treatment for the majority of $\mathrm{T} 3-\mathrm{T} 4$ rectal tumors.

Future challenges in rectal cancer are to improve sphincter preservation and survival.

As for SSP, the benefit of concurrent chemotherapy is still debatable, even with long-interval radiotherapy. One interesting hypothesis is to try to achieve a complete clinical tumor response before surgery (which is different from sterilization of the operative specimen) to influence the surgeon's decision. This could be achieved by endocavitary radiotherapy in association with external beam radiotherapy with or without chemotherapy.

Finally, the design of efficient adjuvant medical treatment is necessary to further reduce development of distant metastases and improve survival.

\section{ACKNOWLEDGMENT}

The authors thank Dr. M. C. Brahimi-Horn for critically reading the manuscript.

\section{REFERENCES}

1. Heald RJ, Moran BJ, Ryall RD, Sexton R, MacFarlane JK. Rectal cancer: the Basingstoke experience of total mesorectal excision, 1978-1997. Arch Surg 1998;133: 894-9.

2. Anonymous. Randomized trial of surgery alone versus surgery followed by radiotherapy for mobile cancer of the rectum. Medical Research Council Rectal Cancer Working Party. Lancet 1996;348:1610-4.

3. O'Connell MJ, Martenson JA, Wieand HS, et al. Improving adjuvant therapy for rectal cancer by combining protracted-infusion Fluorouracil with radiation therapy after curative surgery. $N$ Engl J Med 1994;331:502-7.
4. Colorectal Cancer Collaborative Group. Adjuvant radiotherapy for rectal cancer: a systematic overview of 8,507 patients from 22 randomized trials. Lancet 2001;358:1291-304.

5. Anonymous. Improved survival with preoperative radiotherapy in resectable rectal cancer. Swedish Rectal Cancer Trial. N Engl J Med 1997;336:980-7.

6. Camma C, Giunta M, Fiorica F, Pagliaro L, Craxi A, Cottone M. Preoperative radiotherapy for resectable rectal cancer: a meta-analysis. JAMA 2000;284:1008-15.

7. Frykholm GJ, Glimelius B, Pahlman L. Preoperative or postoperative irradiation in adenocarcinoma of the rectum: final treatment results of a randomized trial and an evaluation of late secondary effects. Dis Colon Rectum 1993;36:564-72.

8. Pahlman L, Glimelius B. Pre or postoperative radiotherapy in rectal and rectosigmoid carcinoma. Report from a randomized multicenter trial. Ann Surg 1990; 211:187-95.

9. Hyams DM, Mamounas EP, Petrelli N, et al. A clinical trial to evaluate the worth of preoperative multimodality therapy in patients with operable carcinoma of the rectum: a progress report of National Surgical Breast and Bowel Project Protocol R-03. Dis Colon Rectum 1997;40:131-9.

10. Sauer R, Becker H, Hohenberger W, et al. Preoperative versus postoperative radiochemotherapy for rectal cancer. N Engl J Med 2004;351:1731-40.

11. Kapiteijn E, Marijnen CA, Nagtegaal ID, et al. Preoperative radiotherapy combined with total mesorectal excision for resectable rectal cancer. $N$ Engl J Med 2001;345:638-46

12. Marijnen CA, Peeters KC, Putter $\mathrm{H}$, et al. Cooperative investigators of the TME trial. Long term results, toxicity and quality of life in the TME trial. Presented at the ESTRO Meeting, Amsterdam, October 24-28, 2004, abstract 283.

13. Marijnen CA, Nagtegaal ID, Klein Kranenbarg E, et al. No downstaging after short-term preoperative radiotherapy in rectal cancer patients. J Clin Oncol 2001;19:1976-84.

14. Dahlberg M, Glimelius B, Graf W, Pahlman L. Preoperative irradiation affects functional results after surgery for rectal cancer. Dis Colon Rectum 1998; 41:543-9.

15. Moore HG, Riedel E, Minsky BD, et al. Adequacy of 1-cm distal margin after restorative rectal cancer resection with sharp mesorectal excision and preoperative combined-modality therapy. Ann Surg Oncol 2003;10:80-5.

16. Francois Y, Nemoz CJ, Baulieux J, et al. Influence of the interval between preoperative radiation therapy and surgery on downstaging and on the rate of sphincter-sparing surgery for rectal cancer: the Lyon R90-01 randomized trial. J Clin Oncol 1999;17:2396. 
17. Pollack A, Zagars GK, Starkschall G, et al. Prostate cancer radiation dose response: results of the M.D. Anderson phase III randomized trial. Int J Radiat Oncol Biol Phys 2002;53:1097-105.

18. Romestaing $\mathrm{P}$, Lehingue $\mathrm{Y}$, Carrie C, et al. Role of a 10Gy boost in the conservative treatment of early breast cancer: results of a randomized trial in Lyon, France. J Clin Oncol 1997;15:963-8.

19. Gerard JP, Chapet O, Ramaioli A, Romestaing P. Longterm control of T2-T3 rectal adenocarcinoma with radiotherapy alone. Int $\mathrm{J}$ Radiat Oncol Biol Phys 2002;54:142-9.

20. Gerard JP, Chapet O, Nemoz C, et al. Improved sphincter preservation in low rectal cancer with highdose preoperative radiotherapy: the LYON R96-02 randomized trial. J Clin Oncol 2004;22:2404-9.

21. Minsky B, Cohen A, Enker W, et al. Preoperative 5 fluorouracil, low-dose leucovorin, and concurrent radiation therapy for rectal cancer. Cancer 1994;73:273-80.

22. Bosset JF, Magnin V, Maingon P, et al. Preoperative radiochemotherapy in rectal cancer: long-term results of a phase II trial. Int $\mathrm{J}$ Radiat Oncol Biol Phys 2000;46:323-7.

23. Garcia-Aguilar J, Hernandez de Anda E, Sirivongs P, Lee $\mathrm{SH}$, Madoff RD, Rothenberger DA. A pathologic complete response to preoperative chemoradiation is associated with lower local recurrence and improved survival in rectal cancer patients treated by mesorectal excision. Dis Colon Rectum 2003;46:298-304.

24. Valentini V, Coco C, Cellini N, et al. Preoperative chemoradiation for extraperitoneal T3 rectal cancer: acute toxicity, tumor response, and sphincter preservation. Int J Radiat Oncol Biol Phys 1998;40:106775.

25. Crane $\mathrm{CH}$, Skibber JM, Feig BW, et al. Response to preoperative chemoradiation increases the use of sphincter-preserving surgery in patients with locally advanced low rectal carcinoma. Cancer 2003;97:517-24.

26. Bosset JF, Calais G, Daban A, et al. Preoperative chemoradiotherapy versus preoperative radiotherapy in rectal cancer patients: assessment of acute toxicity and treatment compliance. Report of the 22921 randomised trial conducted by the EORTC Radiotherapy Group. Eur J Cancer 2004;40:219-24.

27. Bosset JF, Calais G, Mineur L, et al. Preoperative radiation (preoperative RT) in rectal cancer: effect and timing of additional chemotherapy (CT) 5-year results of the EORTC 22921 trial. Oral presentation. Pro- ceedings of ASCO 2005, Orlando, Florida, May 13-17, 2005;23(16s):247s (abstract 3505).

28. Gerard JP, Bonnetain F, Conroy T, et al. Preoperative (preop) radiotherapy (RT) $+/-5 \mathrm{FU} /$ folinic acid (FA) in T3-4 rectal cancers: results of the FFCD 9203 randomized trial. Oral presentation. Proceedings of ASCO 2005, Orlando, Florida, May 13-17, 2005;23(16s):247s (abstract 3504).

29. Bujko K, Nowacki MP, Nasierowska-Guttmejer A, et al. Sphincter preservation following preoperative radiotherapy for rectal cancer: report of a randomized trial comparing short-term radiotherapy $v s$. conventionally fractionated radiochemotherapy. Radiother Oncol 2004;72:15-24.

30. Freyer G, Bossard N, Romestaing P, et al. Addition of oxaliplatin to continuous fluorouracil, l-folinic acid, and concomitant radiotherapy in rectal cancer: the Lyon $\mathrm{R}$ 97-03 phase I trial. J Clin Oncol 2001;19:2433-8.

31. Gerard JP, Chapet $\mathrm{O}$, Nemoz C, et al. Preoperative concurrent chemoradiotherapy in locally advanced rectal cancer with high-dose radiation and oxaliplatincontaining regimen: The Lyon R0-04 phase II trial. J Clin Oncol 2003;21:1119-24.

32. Glynne-Jones R, Sebag-Montefiore D, McDonald A, Falk S, Maughan T. Preliminary phase II SOCRATES study results: Capecitabine combined with oxaliplatin and preoperative radiation in patients with locally advanced rectal cancer. Proceedings of ASCO 2004, New Orleans, Louisiana, June 5-8, 2004;22(14s):263s (abstract 3575).

33. Rodel C, Grabenbauer GG, Papadopoulos T, Hohenberger W, Schmoll HJ, Sauer R. Phase I/II trial of capecitabine, oxaliplatin, and radiation for rectal cancer. J Clin Oncol 2003;21:3098-104.

34. Willett CG, Boucher Y, Tomaso Edi, et al. Direct evidence that the VEGF-specific antibody bevacizumab has antivascular effects in human rectal cancer. Nat Med 2004;10:145-7.

35. Gray RG, Barnwell J, Hills R, McConkey C, Williams N, Kerr D, for the QUASAR Collaborative Group. QUASAR: A randomized study of adjuvant chemotherapy $v$. observation including 3238 colorectal cancer patients. Proceedings of ASCO 2004, New Orleans, Louisiana, June 5-8, 2004 (abstract 3501).

36. James RD, Donaldson D, Gray R, Northover JM, Stenning SP, Taylor IAXIS Collaborators. Randomized clinical trial of adjuvant radiotherapy and 5 fluorouracil infusion in colorectal cancer (AXIS). Br J Surg 2003; 90:1200-12. 